\title{
pnmbalina
}

(8)

\section{A epistemologia interdisciplinar na ciência da informação: implicações na formação do campo científico}

Autor(es): $\quad$ Souza, Edivanio Duarte de; Dias, Eduardo José Wense

Publicado por: Imprensa da Universidade de Coimbra

URL

persistente: URI:http://hdl.handle.net/10316.2/31871

DOI: $\quad$ DOI:http://dx.doi.org/10.14195/978-989-26-0319-3_11

Accessed : $\quad$ 26-Apr-2023 12:32:36

A navegação consulta e descarregamento dos títulos inseridos nas Bibliotecas Digitais UC Digitalis, UC Pombalina e UC Impactum, pressupõem a aceitação plena e sem reservas dos Termos e Condições de Uso destas Bibliotecas Digitais, disponíveis em https://digitalis.uc.pt/pt-pt/termos.

Conforme exposto nos referidos Termos e Condições de Uso, o descarregamento de títulos de acesso restrito requer uma licença válida de autorização devendo o utilizador aceder ao(s) documento(s) a partir de um endereço de IP da instituição detentora da supramencionada licença.

Ao utilizador é apenas permitido o descarregamento para uso pessoal, pelo que o emprego do(s) título(s) descarregado(s) para outro fim, designadamente comercial, carece de autorização do respetivo autor ou editor da obra.

Na medida em que todas as obras da UC Digitalis se encontram protegidas pelo Código do Direito de Autor e Direitos Conexos e demais legislação aplicável, toda a cópia, parcial ou total, deste documento, nos casos em que é legalmente admitida, deverá conter ou fazer-se acompanhar por este aviso. 
Maria Manuel Borges

Elias Sanz Casado

Coordenação

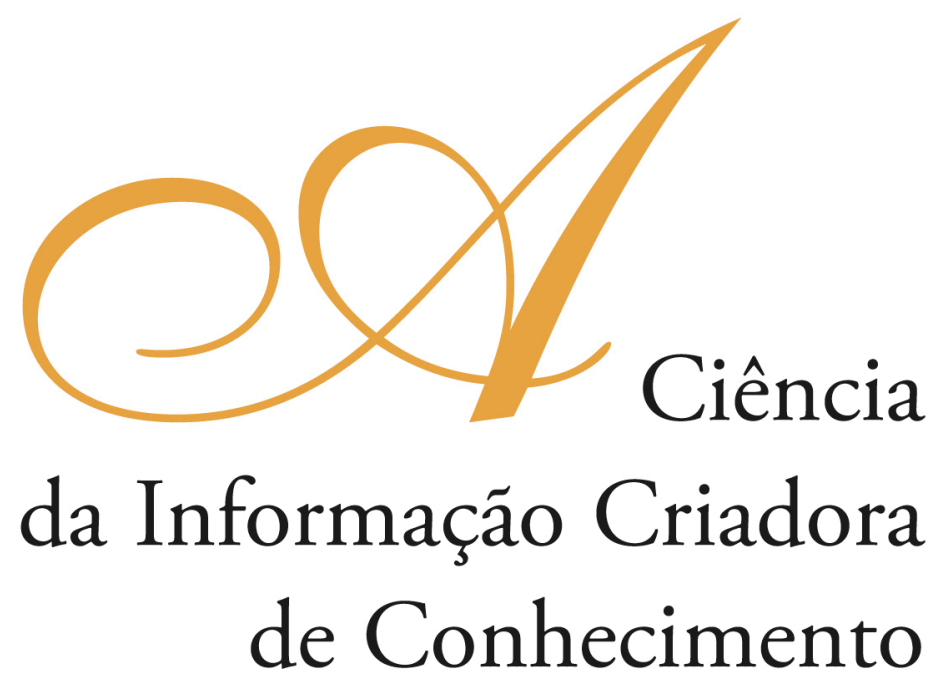

Vol. I

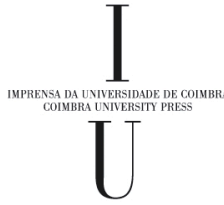

- COIMBRA 2009 


\title{
A Epistemologia Interdisciplinar na Cî̂ncia da Informação: Implicaçốes na Formação do Campo Científico
}

\author{
Edivanio Duarte de Souza \\ Universidade Federal de Alagoas (Brasil) \\ Eduardo José Wense Dias \\ Universidade Federal de Minas Gerais (Brasil)
}

\section{Resumo}

Dedica-se a algumas reflexôes sobre a constituição e a consolidação epistemológicas da Ciência da Informação, guiadas, notadamente pelos contornos das ciências sociais aplicadas.

Tem como objeto de análise empírica artigos publicados em periódicos da área sobre a sua integração disciplinar, no período de 1990 a 2008. Define como categoria de análise as unidades paratextuais e textuais. Apresenta indícios que facultam varias considerações sobre as formaçóes de unidades do discurso de integração disciplinar, na produção científica brasileira. Considera, a partir de seu desenho disciplinar, que a Ciência da Informação necessita de práticas teóricometodológicas confluentes orientadas a construçóes de excedentes epistemológicos, que, em última análise, visam à constituição de sua identidade e, conseqüentemente, à consolidação da área.

\begin{abstract}
Based on the ideas of the applied sciences, this article discusses some reflections towards the constitution and consolidation of the epistemological field of the Information Science. It considers as the object of empiric analyses articles published in journals in the area on their disciplinary integration, in the period 1990-2008. It defines as category of analysis of the paratext and text units. Its also presents some evidences that show many considerations towards the formations of units of the disciplinary integration, in the Brazilian scientific production. Moreover, based on his disciplinary design, it considers that the Information Science needs some confluent methodological theoretical practices which guide the construction of the epistemological surplus that, after all, aims at the constitution of its identity and, consequently, the consolidation of the area.
\end{abstract}

\section{Introdução}

Com aproximadamente meio século de origem, a Ciência da Informação ainda não dispóe de um estatuto disciplinar consolidado com fundamentos teórico-metodológicos próprios, que a caracterize e a identifique como campo de conhecimento, em todos os seus contornos. O desenvolvimento de suas teorias e metodologias sempre esteve, em menor ou maior grau, atrelado a áreas com as quais busca construir constantemente interlocuções. Essa dificuldade de consolidação epistemológica pode estar relacionada a uma série de questóes que vão desde a complexidade da área à forma como os 
pesquisadores selecionam seus objetos de estudo e delimitam seus problemas e hipóteses de pesquisa.

As possibilidades de integração disciplinar ${ }^{1}$ exigem esse modo de pensar, uma vez que, ao mesmo tempo em que se coloca no campo da superação de hiperespecialização, exige a definiçáo de contornos disciplinares que solidificam as particularidades nessa relação dialógica. A inexistência desses contornos possibilita o surgimento daquilo que Domingues (2005) denominou de zonas de indefinição e domínios de ignorância.

Sob essa ótica, pode-se perceber, sem maiores esforços, que a Ciência da Informação vem tendo dificuldade na efetivação dessa vigília epistemológica e, mais ainda, nas rupturas com o pensamento moderno e até mesmo clássico. Assim, grande parte de sua fundamentação epistemológica é originária de outras áreas, tais como Biblioteconomia, Documentação, Administração e Ciência da Computação, com forte apego a definiçóes empíricas, em detrimento de construçóes teóricometodológicas mais consolidadas.

Nos movimentos que vão da constituição ao desenvolvimento do campo científico da Ciência da Informação, há, segundo Dias (2002), pelo menos, dois entendimentos que apontam para desenhos epistemológicos diferentes do seu campo científico, um mais amplo, que se apresenta como mais usado no Brasil; e outro mais restrito, que procura estudar a Ciência da Informação de várias formas, porém, todas procurando estabelecer diferenças com outros campos. O fato é que esses estão sempre, em maior ou menor grau, atrelados as discussôes sobre as relações disciplinares construídas. De forma mais precisa, o discurso de integração disciplinar, especificamente, a interdisciplinaridade, tem sido o ponto de partida da constituiçáo do campo epistemológico da Ciência da Informação.

Por outro lado, é preciso considerar que, na literatura da área, pouco se tem dedicado aos estudos epistemológicos e interdisciplinares, sobretudo, aqueles que procuram compreender as implicaçóes das metodologias integradoras na constituição e consolidação do campo científico da Ciência da Informação. Com efeito, faz-se necessário destacar que, para o estabelecimento de efetivas relaçóes interdisciplinares, é condição necessária a existência de, no mínimo, duas disciplinas com reconhecida autonomia que mantenham uma construção discursiva recíproca. E, nessa perspectiva, a Ciência da Informação precisa, em primeira instância, constituir seu campo teórico e epistemológico de forma minimamente consolidada para atuar ativamente no processo interdisciplinar.

Este trabalho apresenta os resultados parciais da pesquisa de doutoramento, que tem como objetivo analisar a construção do discurso interdisciplinar na Ciência da Informação, a partir de referenciais teóricos nacionais, e sua relação com a construção da autonomia do campo científico. Esses resultados correspondem à primeira fase

\footnotetext{
1 A integração disciplinar compóe-se da rede terminológica do modelo triádico (pluri, inter e trans), bem como da noção de continuum disciplinar propostos por Pombo (1994). Além de apresentar a diferença entre esses níveis de integração, a autora esclarece que esta se dá por intermédio de movimentos que vão de um paralelismo pluridisciplinar ao perspectivismo e à convergência interdisciplinar, e, desta, ao holismo e à unificação transdisciplinar. A pluridisciplinaridade corresponde ao pólo mínimo, a transdisciplinaridade ao pólo máximo e a interdisciplinaridade às diversas integraçóes possíveis entre esses dois extremos.
} 
da pesquisa que se constituem, a partir da construção do corpus teórico e análise das informações referenciais, nos primeiros indícios das condiçôes de produção do discurso de integração disciplinar na Ciência da Informação, notadamente a interdisciplinaridade que se apresenta com um dos fundamentos do campo científico.

\section{Fundamentos epistemológicos da ciência da informação}

Nos últimos anos, em alguns estudos sobre os fundamentos da Ciência da Informação, têm sido recorrentes as afirmativas de que os pesquisadores devem procurar aprofundar os estudos epistemológicos visando à sua consolidação como campo de conhecimento dedicado, especificamente, ao estudo do fenômeno informacional na sua dinâmica e complexidade. Nesse intento, alguns estudiosos a exemplo de Jesse Shera, Rafael Capurro e Tefko Saracevic, têm lançado mão de algumas hipóteses e procurado argumentá-las e justificá-las como constituintes de abordagens disciplinares dominantes. A definição de perspectivas epistemológicas também tem apresentado algumas diferenças conceituais e de ponto de vista.

De modo geral, a origem da Ciência da Informaçáo, ocorrida em meados do século passado, é apontada como devida ao aumento exponencial da produçáo de informaçóes e a conseqüente necessidade de análise, tratamento e organização para sua posterior recuperação. Le Coadic (1996) esclarece que o desenvolvimento de informaçôes gerais, científicas e técnicas, e de sistemas de informação imprimiu a necessidade de uma ciência que se dedicasse ao estudo de informaçáo, metodologias e técnicas desenvolvidas no seu interior.

Nesse sentido, Saracevic (1996) destaca que a compreensão histórica da Ciência da Informação, incluindo o passado, o presente e o futuro, está inexoravelmente ligada às características ou razóes que constituem sua tríade: natureza originalmente interdisciplinar; fundamento na tecnologia da informaçáo; e papel ativo na evolução da sociedade da informação. A proposta inicial era tornar acessível a massa crescente de documentos. Vários pesquisadores, especialmente cientistas e engenheiros, se dedicaram a desenvolver estudos e programas estratégicos com o intuito de apresentar algumas soluçóes para a questão em aberto, com destaque inicial para o desenvolvido por Vannevar Bush, autor do Memex, que tinha como meta duplicar os processos mentais de forma artificial, através da associação de idéias (SARACEVIC, 1996).

Numa síntese da "evolução" dos fundamentos históricos e epistemológicos da Ciência da Informação, Capurro (2003) agrupa as pesquisas e a produção do campo em três paradigmas ${ }^{2}$ : físico, cognitivo e social. Cada um desses apresenta abordagens e

\footnotetext{
${ }^{2}$ A constituição de um paradigma compreende “[...] as realizaçōes científicas universalmente reconhecidas que, durante algum tempo, fornecem problemas e soluçóes modelares para uma comunidade de praticantes de uma ciência” (KUHN, 2007, p. 13). Inobstante ao conceito de paradigma na Ciência da Informação não ter precisamente amplitude dada por Kuhn, representa algumas perspectivas ou orientações teóricometodológicas desenvolvidas e dominantes na área, que apontam para a conformação de uma matriz disciplinar também presente nas discussōes deste autor.
} 
orientaçóes próprias no que concerne ao conceito de Ciência de Informação, à construção de seu objeto de estudo e aos desenhos teórico-metodológicos que os fundamentam.

O paradigma físico, de acordo com Capurro (2003), tem como fundamentos a Teoria Matemática da Comunicação de Claude Shannon e Warren Weaver e a Cibernética de Nobert Wiener. Trata-se do modelo simplista de comunicação composto por três elementos - um emissor, uma mensagem e um receptor. A informação é entendida como elemento objetivo, podendo, portanto, ser medida e quantificada. Essa visáo decorre da forma como a mensagem é conduzida e controlada nesse sistema. A funcionalidade do sistema impunha que a mensagem ou sinais elétricos, como precisamente era denominada, deveria ser reconhecida univocamente em principio pelo receptor como são pelo emissor. Além desse controle das condiçóes ideais, o sistema necessitava também da ausência de ruído que perturbasse o processo de transmissão.

De acordo com Capurro (2003), foram as críticas a essa visão da informação como coisa (Buckland, 1991) e aos processos tecnicistas de recuperação de informação (Cranfield, 1957 apud Capurro, 2003) que conduziram ao surgimento do paradigma cognitivo. Formulado por Brookes e sob fortes influências dos três mundos de Karl Pooper - o físico, o da consciência ou dos estados psíquicos e o do conteúdo intelectual dos livros ou das teorias científicas, o paradigma cognitivo traz duas mudanças significativas, uma vez que possibilita a distinção nítida entre o documento-suporte e a informação, e acrescenta o usuário como sujeito cognoscente possuidor de modelos mentais do mundo exterior (Capurro, 2003). Pode-se dizer que, do ponto de vista da concepção de informação e de usuário, houve pequenos avanços, uma vez que nesta abordagem a informação é considerada como ente separado do usuário que é, por sua vez, do contexto complexo de significação.

É justamente a ausência de elo entre os mundos material e cognitivo, em outros termos entre mente e mundo, que se encontra a maior crítica ao paradigma cognitivo. Sendo assim, o usuário passa a fazer parte do sistema de recuperação de informação, mas não é considerado na sua completude como sujeito sócio-cognitivo e sim como um sujeito unicamente com a dimensão psicológica. $\mathrm{O}$ paradigma cognitivo abre espaço para o paradigma social, que se apresenta de forma mais ampla e possibilita, portanto, uma melhor compreensão do fenômeno informacional.

A perspectiva paradigmática social procura estabelecer abordagens contextuais, fundamentada, sobretudo, na epistemologia das "investigaçóes filosóficas" de Wittgenstein, nas teorias do discurso como relaçóes de poder de Foucault e na hermenêutica do "existir" humano de Heidegger. Todas essas correntes epistemológicas, conforme destacou Capurro (2003), influenciam a Ciência da Informaçáo, notadamente, o processo de representação da informação.

O fato de essas perspectivas não serem excludentes, mas complementares, demonstra a dimensão e complexidade da constituição de um domínio epistemológico do campo da Ciência da Informação. Primeiro porque, guardadas as devidas ressalvas, cada uma dessas perspectivas tem suas particularidades, seus pontos críticos e efetivas contribuiçóes, em determinados momentos e contextos. Essa abrangência do campo da Ciência da Informação concorre cada vez mais para a efetiva necessidade de interlocuçôes com outras áreas afins. Por outro lado, faz-se necessário observar que a prática dessas relaçóes interdisciplinares exige um maior esforço dos pesquisadores da área no sentido de produzir o que González de Gómez (2000) denominou de excedente epistemológico, 
ou seja, obter de suas pesquisas conteúdos diferentes daqueles advindos de outras áreas, portanto, com identidade própria.

\section{A epistemologia interdisciplinar no campo da ciência da informação: complexidade e implicaçóes}

Passado aproximadamente meio século de seu surgimento, um retrospecto sobre seu campo de conhecimento possibilita a compreensão de que "de prática de organização, a Ciência da Informação tornou-se, portanto, uma ciência social que se apóia em uma tecnologia também rigorosa. Tem por objeto o estudo das propriedades gerais da informação (natureza, gênese e efeito) [...]" (LE COADIC, 1996, p. 26). A Ciência da Informação se insere no rol de ciências que buscam a compreensão dos problemas da sociedade de forma situada e contextualizada, para propor soluçóes adequadas. Isso imprime um redimensionamento do seu campo epistemológico a partir de interlocuçôes contínuas entre as três perspectivas paradigmáticas apresentadas por Capurro (2003).

Com efeito, é preciso considerar que esse espectro de dispersão epistemológica exige maior esforço teórico-metodológico do campo da Ciência da Informação nas construçóes de integração disciplinar, notadamente, nas relaçôes interdisciplinares. Isso se deve principalmente ao fato de que, ao mesmo tempo em que esta se coloca nos espaços da superação da hiper-especialização, exige a definição de contornos disciplinares que a diferenciam, que a identificam, que a particularizam (Morin, 20--?). A inexistência desses contornos possibilita o surgimento de zonas de indefinição e domínios de ignorância próprios de investidas transdisciplinares (Domingues, 2005).

Ao se caracterizar como essencialmente interdisciplinar (Saracevic, 1996), a Ciência da Informação assume a complexidade e a dificuldade no estabelecimento dos compromissos teórico-metodológicos. Além de os pesquisadores do campo ser originários de diferentes áreas, há uma forte tendência a trabalhar nas fronteiras interdisciplinares, a partir de recortes empíricos vinculados à sua área de origem. Assim, é preciso considerar, de acordo com Kuhn (2007), que, ao exercerem suas práticas profissionais em diferentes mundos, esses pesquisadores vêem objetos diferentes quando olham de um mesmo ponto para a mesma direção.

A Ciência da Informação, nos seus projetos de construção de conhecimento interdisciplinar e de consolidação epistemológica, precisa ficar atenta às práticas de integração disciplinar, considerando que a constituição de identidade de seu campo só se efetivará a partir da construção dos excedentes epistemológicos (González de Gómez, 2000). Alguns autores, a exemplo de Le Coadic (1996), entendem que, nesse campo, a teoria se apresenta atrasada em relação ao empírico e há ausências de ligação entre os dois.

Por outro lado, as discussôes aqui empreendidas partem da compreensão de que o enfoque desenvolvido a partir da necessidade de definição da matriz disciplinar do campo epistemológico da Ciência da Informação é, se não mais, pelo menos tão significativo quanto algumas investidas interdisciplinares no processo de consolidação e construção de sua autonomia. A Ciência da Informaçáo parece apresentar, por outro lado, característica ingênua, se não superficial. Assim, não seria exagero insistir que 
esta prática conduz um modo de olhar, no mínimo, incompleto. Se o que se afirma é procedente, segue-se, então, que um dos primeiros passos no processo de consolidação epistemológica do campo atine à maior aproximação e rigor na construçáo das heurísticas que cercam esse espaço discursivo, num movimento de recorrência, pautado em constante vigilância e ruptura epistemológicas (Bachelard, 1996).

Procurar renovar e confirmar as especificidades da Ciência da Informação parece ser as primeiras investidas que devem ser realizadas neste processo. Uma especificidade que é difícil, se não impossível, de se estabelecer com fundamentos num discurso interdisciplinar espontâneo e permissivo. Trata-se de buscar outros horizontes para além de um modismo discursivo que a coloca, segundo Silva (2008), num náo-lugar. Essa prática, nas palavras do autor, resulta na sua condenação a uma vacuidade espumante que uma vez desfeita deixa ver as âncoras das disciplinas dominantes que se escondem debaixo da espuma. Ainda de acordo com o autor, essa prática, embora seja fácil de ser desmontada, é visivelmente praticada na elaboração de dissertaçóes e teses, no Brasil e na Espanha.

É preciso considerar que a relação disciplinar é definida quase sempre em função dos processos informacionais desenvolvidos no interior das disciplinas praticantes, ou seja, estão, ao menos numa primeira aproximação, mais nos espaços da aplicação e da prática profissional que nas construçóes epistemológicas de integração disciplinar. Nas relaçôes estabelecidas com a Biblioteconomia, por exemplo, a Ciência da Informação tem um forte apego à "estrutura informacional" (suporte e instituição) em detrimento do "acontecimento informacional" (significação), embora o fenômeno informacional compreenda essas duas esferas, conforme Saracevic (1996). Por outro lado, no estabelecimento de relaçôes disciplinares com a Lingüística, há uma sobreposição desta em detrimento daquela.

O fato é que tanto quanto existirem áreas que, de alguma forma, versam sobre o processamento da informação, haverá abordagens e enfoques diferentes e, conseqüentemente, possibilidades de relaçôes disciplinares em níveis e enfoques diversos. O que não autoriza, contudo, afirmar que em função disso a Ciência da Informação é interdisciplinar por natureza e correlaciona epistemologicamente com todas essas áreas.

\section{Definição e organização do corpus analítico}

A identificação e a seleção do corpus analítico partem da premissa de que a compreensão da constituição e desenvolvimento de um campo científico pode se dá a partir do estudo de sua produção científica, uma vez que esta materializa e evidencia os compromissos teórico-metodológicos que vêm sendo construídos. Em última análise, esta possibilita a compreensão do comportamento de seus pesquisadores, no âmbito individual e na relação com seus pares. Refere-se, portanto, à construção de indicadores de produçáo científica sobre a integração disciplinar, no campo da Ciência da Informação, e das relaçóes que podem ser estabelecidas a partir desses indicadores.

Nesse sentido, compóem o universo da pesquisa os artigos publicados nos periódicos científicos brasileiros Ciência da Informação (ISSN 1518-8353), Data Grama Zero - Revista de Ciência da Informação (ISSN 1517-3801) e Perspectivas em Ciência da 
Informação (ISSN 1413-9936), doravante CI, DGZ e PCI, respectivamente, nos anos de 1990 a 2008, período de início de consolidação epistemológica do campo. Além disso, faz-se necessário destacar que os periódicos analisados são editados, respectivamente, pelo pesquisador Aldo de Albuquerque Barreto, pelo Instituto Brasileiro de Informação em Ciência e Tecnologia, e pela Escola de Ciência da Informação da Universidade Federal de Minas Gerais, e se encontram, de acordo com a classificaçáo da Base de Dados Qualis mantida pela Coordenação de Aperfeiçoamento de Ensino Superior $(\mathrm{CAPES})^{3}$, entre aqueles melhor qualificados, no conjunto de periódicos brasileiros especializados em Ciência da Informaçáo.

$\mathrm{Na}$ definição do corpus analítico, foram analisados 1222 (hum mil, duzentos e vinte e dois) artigos distribuídos da seguinte forma: 689 da CI, 248 artigos da DGZ, e 285 da PCI.

Essa pré-análise para identificação dos artigos que abordam e/ou mencionam a integração interdisciplinar foi realizada a partir da leitura dos títulos, resumos e palavras-chave dos artigos, quando existentes, bem como da busca no texto de expressôes que designem nomeadamente a integração disciplinar (inter, multi, pluri e transdisciplinaridade).

Os dados foram tabulados e analisados de acordo com as seguintes unidades de análise: freqüência do discurso da integração disciplinar, tipologia de autor, produtividade de autor e temáticas. No processo analítico, as três últimas unidades de análises referemse apenas à produção científica que veicula o discurso da integração disciplinar. Os artigos foram classificados com base nos temas apresentados por Oddone e Gomes (2004), com alguns acréscimos tais como gestão da informação e do conhecimento, e ontologias.

\section{A integração disciplinar na produção científica da ciência da informação: breves reflexóes}

As discussóes aqui empreendidas partem da noção de que o conjunto de relaçóes estabelecidas entre os indicadores da produção analisada permitem a definiçáo de alguns elementos que contribuem com a compreensão do campo discursivo dessa produção e, para além disso, com os indícios da conformação do campo científico da Ciência da Informação. Nessa perspectiva, a primeira observação a ser feita diz respeito à presença do discurso da integração disciplinar na Ciência da Informação.

Esses resultados evidenciam uma presença marcante do discurso da integraçáo disciplinar na produção científica da Ciência da Informação, com uma média de $34 \%$ da produção analisada. Esses resultados corroboram com o entendimento de que uma série de estudos da Ciência da Informação realizados, no Brasil, tem por base o primeiro dos elementos da tríade do campo apontada por Saracevic (1996): natureza originalmente interdisciplinar, fundamento na tecnologia da informação e papel ativo na sociedade da informação.

\footnotetext{
${ }^{3}$ Órgão do Ministério da Educação brasileiro que tem, entre suas principais responsabilidades, avaliar e certificar os programas de pós-graduação no país.
} 
Tabela 1 - Recorte do Corpus Teórico

\begin{tabular}{|l|c|c|c|c|c|c|}
\hline \multirow{2}{*}{ Periódicos } & \multicolumn{4}{|c|}{ Artigos } \\
\cline { 2 - 7 } & \multicolumn{2}{|c|}{ ID $^{\mathbf{1}}$} & \multicolumn{2}{c|}{ Outros } & \multicolumn{2}{c|}{ Total } \\
\hline & $f(\mathrm{x})$ & $f(\%)$ & $f(\mathrm{x})$ & $f(\%)$ & $f(\mathrm{x})$ & $f(\%)$ \\
\hline $\begin{array}{l}\text { Data Grama Zero - Revista de Ciência da } \\
\text { Informaçáo }\end{array}$ & 96 & 38,71 & 152 & 61,29 & 248 & 100 \\
\hline Ciência da Informaçấo & 204 & 29,61 & 485 & 70,39 & 689 & 100 \\
\hline Perspectivas em Ciência da Informaçáo & 95 & 33,33 & 190 & 66,67 & 285 & 100 \\
\hline Total & 395 & 32,32 & 827 & 67,68 & 1222 & 100 \\
\hline
\end{tabular}

Fonte: Pesquisa empírica (dez./2008-jul./2009).

Com efeito, é preciso considerar que a definição da integração disciplinar, mais precisamente a interdisciplinaridade, como um dos fundamentos da constituiçáo do seu campo científico implica na necessidade de estudos epistemológicos aprofundados e com maior rigor teórico-metodológico. De outra forma, a prática científica orientada à constituiçấo e à consolidação do campo científico exige maior vigilância epistemológica, nos espaços da integraçáo disciplinar, para possibilitar a aproximação da autonomia científica (Bourdieu, 1983). Essa preocupaçáo se deve ao fato de que, segundo Pombo (1994), a interdisciplinaridade aparece, muitas vezes, como uma mera palavra flutuante e ambígua, que serve para caracterizar projetos vagos, nebulosos e com contornos indefinidos. Dependendo das estratégias usadas, as demais práticas de integraçáo disciplinar, como a multi e a pluridisciplinaridade, se constituem em meras justaposiçôes de conteúdos, que se constituem em obstáculos epistemológicos à consolidação de um campo científico.

A autoria se configura como um importante elemento analítico nos espaços da integração disciplinar. Nesse sentido, Domingues (2005) esclarece que este projeto de uma nova topa de conhecimento tem por fundamento a constituição de inteligentes coletivos, que possibilitem o compartilhamento de conhecimentos e a cooperaçáo entre especialistas.

Tabela 2 - Tipologia de Autoria

\begin{tabular}{|l|c|c|c|c|c|c|c|c|c|}
\hline \multicolumn{1}{|c|}{ Autoria } & \multicolumn{2}{|c|}{ DGZ } & \multicolumn{2}{|c|}{ CI } & \multicolumn{2}{c|}{ PCI } & \multicolumn{2}{|c|}{ Total } \\
\cline { 3 - 11 } & $f(\mathrm{x})$ & $f(\%)$ & $f(\mathrm{x})$ & $f(\%)$ & $f(\mathrm{x})$ & $f(\%)$ & $f(\mathrm{x})$ & $f(\%)$ \\
\hline Individual & 1 & 49 & 51,04 & 134 & 65,69 & 51 & 53,68 & 234 & 59,24 \\
\hline \multirow{4}{*}{ Co-autoria } & 2 & 33 & 34,38 & 32 & 15,69 & 21 & 22,11 & 86 & 21,77 \\
\cline { 2 - 11 } & 3 & 11 & 11,46 & 24 & 11,76 & 13 & 13,68 & 48 & 12,15 \\
\cline { 2 - 11 } & 4 & 2 & 2,08 & 9 & 4,41 & 7 & 7,37 & 18 & 4,57 \\
\hline & 5 & 0 & 0 & 3 & 1,47 & 2 & 2,11 & 5 & 1,27 \\
\hline & 6 & 0 & 0 & 0 & 0 & 1 & 1,05 & 1 & 0,25 \\
\hline & 9 & 0 & 0 & 1 & 0,49 & 0 & 0 & 1 & 0,25 \\
\hline & 10 & 1 & 1,04 & 0 & 0 & 0 & 0 & 1 & 0,25 \\
\hline & 12 & 0 & 0 & 1 & 0,49 & 0 & 0 & 1 & 0,25 \\
\hline Total & & 96 & 100 & 204 & 100 & 95 & 100 & 395 & 100 \\
\hline
\end{tabular}

Fonte: Pesquisa empírica (dez./2008-jul./2009). 
Considerando que boa parte da produção científica da Ciência da Informação tem por base o fundamento da integraçáo disciplinar, no Brasil, esta ainda apresenta um alto grau de individualidade. Naturalmente que não se pode deixar de observar que, em se tratando de artigos científicos, essa produção é, de alguma forma, respaldada nos acordos estabelecidos pelos conselhos consultivos e editoriais, que firmam o que Kuhn (2007) denominou de consenso aparente.

Outra importante unidade de análise da produção científica, que complementa a tipologia de autoria, corresponde ao índice de produtividade dos autores, uma vez que sinaliza a origem e ordem desse discurso por intermédio da formação desses autores, da participação em grupos de pesquisa, da filiaçáo institucional, entre outros vínculos existentes.

Tabela 3 - Índice de Produtividade Relativa

\begin{tabular}{|l|c|c|c|c|c|c|}
\hline \multicolumn{7}{|c|}{ Autores } \\
\hline Artigos & \multicolumn{2}{|c|}{ DGZ } & \multicolumn{2}{c|}{ CI } & \multicolumn{2}{c|}{ PCI } \\
\hline & $f(\mathrm{x})$ & $f(\%)$ & $f(\mathrm{x})$ & $f(\%)$ & $f(\mathrm{x})$ & $f(\%)$ \\
\hline 1 & 116 & 84,67 & 268 & 90,24 & 127 & 86,99 \\
\hline 2 & 15 & 10,95 & 20 & 6,73 & 12 & 8,22 \\
\hline 3 & 5 & 3,65 & 6 & 2,02 & 4 & 2,74 \\
\hline 4 & 1 & 0,73 & 0 & 0 & 0 & 0 \\
\hline 5 & 0 & 0 & 2 & 0,67 & 3 & 2,05 \\
\hline 6 & 0 & 0 & 1 & 0,34 & 0 & 0 \\
\hline Total & 137 & 100 & 297 & 100 & 146 & 100 \\
\hline
\end{tabular}

Fonte: Pesquisa empírica (dez./2008-jul./2009).

De acordo com os resultados da pesquisa na tabela acima, há um alto grau de rotatividade de autores na produçáo do discurso da integração disciplinar, uma vez que, no universo pesquisado, em média, $87 \%$ dos autores produziram apenas um artigo. De alguma forma, esse dado pode demonstrar certa imaturidade da produção científica da integração disciplinar. Aqui duas questóes precisam ser lembradas a partir de Bachelard (1996), Bourdieu (1983), e Kuhn (2007), quais sejam os estágios de desenvolvimento da prática científica e o progresso científico. A primeira, de acordo com os dois primeiros autores, é que a construção do objeto de estudo, em particular, e o processo científico, de forma ampla, dão-se num movimento dinâmico de aproximaçóes, recorrências e retificações. Inobstante a compreensão de que o progresso científico não se desenvolve a partir de um continuum, considera-se que a prática científica exige que o pesquisador, embora de forma não causal, percorra alguns estágios que potencializem melhor aproximação da realidade.

Em Kuhn (2007), faz-se necessário considerar que uma disciplina é menos determinada pelo seu objeto do que pelo seu objetivo, e, em sendo assim, o objeto construído corresponde ao objeto instruído em relaçóes teóricas bem definidas, que promovem a realização de experiências fecundas.

Por outro lado, Kuhn (2007) assevera que pesquisadores iniciantes tendem a colocar num mesmo grau de relevância os diversos problemas de pesquisa a eles apresentados, direcionando para as armadilhas dos obstáculos epistemológicos apontados por Bachelard (1996), notadamente o imediatismo e o generalismo. 
Ainda considerando o índice de produtividade na área de integração disciplinar na Ciência da Informação, no Brasil, foi possível estabelecer os autores que mais produziram no âmbito dessa temática.

$\mathrm{Na}$ tabela abaixo, estão presentes dez autores que mais produziram artigos que evocam o discurso da integração disciplinar. Isso pode estar relacionado, pelo menos, a duas questôes, quais sejam a participação ativa desses autores na produção científica da Ciência da Informação como um todo, já que não houve um comparativo com a produção onde não se encontra presente este discurso, e a maior presença da prática da integraçáo disciplinar nas suas respectivas áreas de atuação. Faz-se necessário apenas lembrar que o critério de seleçáo dos artigos corresponde à presença desse discurso, o que, naturalmente, não autoriza, neste momento, qualquer conclusão de cunho mais qualitativo.

Tabela 4 - Autores de Maior Produtividade

\begin{tabular}{|l|c|}
\hline Autores & Artigos $\mathbf{f ( x )}$ \\
\hline Feire, Isa Maria & 10 \\
\hline González de Gómez, Maria Nélida & 10 \\
\hline Barbosa, Ricardo Rodrigues & 7 \\
\hline Lara, Marilda Lopes Ginez de & 6 \\
\hline Pinheiro, Lena Vânia Ribeiro & 6 \\
\hline Silva, Antônio Braz de Oliveira e & 6 \\
\hline Barreto, Aldo de Albuquerque & 5 \\
\hline Bufrem, Leila Santiago & 5 \\
\hline Miranda, Antônio Lisboa Carvalho de & 5 \\
\hline Moura, Maria Aparecida & 5 \\
\hline
\end{tabular}

Fonte: Pesquisa empírica (dez./2008-jul./2009).

Contrariamente ao que foi destacado no que concerne àqueles autores que produziram um único artigo que versam sobre a integração disciplinar, estes autores possivelmente possuem construções teórico-metodológicas mais instruídas, para usar as palavras de Bourdieu (1983), em função das suas investidas no processo dinâmico de aproximações, recorrências e retificaçóes, conforme sugere Bachelard (1996). Embora não se possa afirmar de forma mais efetiva, o fato é que estes pesquisadores tiveram oportunidade para ratificar ou retificar suas construçóes sobre a integração disciplinar. Acrescente-se a isso que, inobstante a ausência de elementos sobre a formação, os vínculos institucionais e, conseqüentemente, a atuação, neste trabalho, sem maiores esforços, pode-se afirmar que se trata de pesquisadores que têm se dedicado aos estudos do campo de Ciência da Informação, nas suas respectivas áreas de atuação, especificamente naquelas onde estão mais presentes estudos e práticas de integração disciplinar (aspectos teóricos, produção e comunicação científica, e gestão da informação e do conhecimento).

No que se refere ao idioma da produção sobre a integração disciplinar, na Ciência da Informação, pode-se afirma que a maior parte da produção se encontra em português, uma vez que se trata da vernácula do Brasil, com uma pequena participaçáo de outros idiomas, destacando o espanhol com aproximadamente $6 \%$ da produçáo. 
Tabela 5 - Distribuição Relativa do Idioma

\begin{tabular}{|c|c|c|c|c|c|c|c|c|}
\hline \multirow{3}{*}{ Idioma } & & & \multicolumn{2}{|c|}{ Artigos } & \multirow{2}{*}{\multicolumn{2}{|c|}{ PCI }} & & \\
\hline & & & & & & & \multicolumn{2}{|c|}{ TOTAL } \\
\hline & $f(\mathrm{x})$ & $f \%)$ & $f(x)$ & $f(\%)$ & $f(x)$ & $f(\%)$ & $f(\mathrm{x})$ & $f(\%)$ \\
\hline Espanhol & 7 & 7,29 & 15 & 7,35 & 0 & 0 & 22 & 5,57 \\
\hline Francês & 0 & 0 & 1 & 0,49 & 0 & 0 & 1 & 0,25 \\
\hline Inglês & 0 & 0 & 3 & 1,47 & 0 & 0 & 3 & 0,76 \\
\hline Português & 89 & 92,71 & 185 & 90,69 & 95 & 100 & 369 & 93,42 \\
\hline Total & 96 & 100 & 204 & 100 & 95 & 100 & 395 & 100 \\
\hline
\end{tabular}

Fonte: Pesquisa empírica (dez./2008-jul./2009).

Numa análise combinada entre os índices de produtividade dos autores e o idioma em que são publicados os artigos, pode-se afirmar que a cooperação estrangeira ainda é bastante incipiente na produção científica do campo, no Brasil. Isso não exclui certamente as significativas contribuiçóes de renomados autores estrangeiros tais como Biger Hjorland, Rafael Capurro, Tefko Saracevic, YvesFrançois Le Coadic, entre outros. O fato é que o avanço da Ciência da Informação, no Brasil, em particular, e no mundo, como um todo, exige a construção de inteligentes coletivos que possibilitem maior cooperação na construção do conhecimento integrado, conforme destacou Domingues (2005).

Tabela 6 - Distribuição de Temáticas

\begin{tabular}{|c|c|c|c|c|c|c|c|c|}
\hline \multicolumn{9}{|c|}{ Artigos } \\
\hline Temáticas & \multicolumn{2}{|c|}{ DGZ } & \multicolumn{2}{|c|}{ CI } & \multicolumn{2}{|c|}{ PCI } & \multicolumn{2}{|c|}{ TOTAL } \\
\hline & $f(x)$ & $f \%)$ & $f(x)$ & $f(\%)$ & $f(\mathrm{x})$ & $f(\%)$ & $f(\mathrm{x})$ & $f(\%)$ \\
\hline $\begin{array}{l}1 \text { - Aspectos Teóricos e Gerais da } \\
\text { Ciência da Informaçáo }\end{array}$ & 27 & 28,13 & 33 & 16,18 & 23 & 24,21 & 83 & 21,01 \\
\hline $\begin{array}{l}2 \text { - Formação Profissional e } \\
\text { Mercado de Trabalho }\end{array}$ & 11 & 11,46 & 17 & 8,33 & 14 & 14,75 & 42 & 10,63 \\
\hline $\begin{array}{l}\text { 3- Gerência de Serviços e Unidades } \\
\text { de Informaçáo }\end{array}$ & 10 & 10,41 & 19 & 9,31 & 17 & 17,89 & 46 & 11,66 \\
\hline $\begin{array}{l}4 \text { - Estudos de Usuário, Demanda } \\
\text { e Uso da Informação e de Unidades } \\
\text { de Informaçáo }\end{array}$ & 0 & 0 & 7 & 3,43 & 7 & 7,37 & 14 & 3,54 \\
\hline $\begin{array}{l}\text { 5- Comunicação, Divulgaçáo e } \\
\text { Produção Editorial }\end{array}$ & 8 & 8,33 & 33 & 16,18 & 17 & 17,89 & 58 & 14,68 \\
\hline 6 - Informação, Cultura e Sociedade & 3 & 3,13 & 19 & 9,31 & 2 & 2,11 & 24 & 6,08 \\
\hline $\begin{array}{l}7 \text { - Legislaçáao, Políticas Públicas de } \\
\text { Informaçâo e de Cultura }\end{array}$ & 9 & 9,38 & 24 & 11,77 & 4 & 4,21 & 37 & 9,37 \\
\hline $8-$ Tecnologias da Informaçáo & 8 & 8,33 & 24 & 11,77 & 1 & 1,05 & 33 & 8,35 \\
\hline $\begin{array}{l}9 \text { - Processamento, Recuperaçáo e } \\
\text { Disseminaçáo da Informaçáo }\end{array}$ & 13 & 13,54 & 20 & 9,8 & 9 & 9,47 & 42 & 10,63 \\
\hline $10-$ Assuntos Correlatos e Outros & 7 & 7,29 & 8 & 3,92 & 1 & 1,05 & 16 & 4,05 \\
\hline Total & 96 & 100 & 204 & 100 & 95 & 100 & 395 & 100 \\
\hline
\end{tabular}

Fonte: Pesquisa empírica (dez./2008-jul./2009). 
A definição das áreas onde o discurso da integração disciplinar se faz presente parece ser bastante relevante para esta pesquisa, uma vez que grande parte das discussóes acerca da interdisciplinaridade na Ciência da Informação se encontra vinculada à definição das temáticas como espaços das relaçóes interdisciplinares construída com outras áreas do conhecimento (Saracevic, 1996).

A análise dos resultados evidencia, no cômputo geral, a maior presença do discurso da prática da integração disciplinar nas temáticas "1 Aspectos Teóricos e Gerais da Ciência da Informaçáo" e "5 Comunicação, Divulgação e Produção Editorial”. Tratase de uma situação bastante compreensível por duas razóes. Primeiro porque um dos fundamentos do campo científico, conforme destacou Saracevic (1996), encontra-se na característica interdisciplinar, o que implica num discurso teórico sobre a prática de integração disciplinar. Segundo porque quando são realizados estudos sobre a produção científica do campo, essa característica é sublinhada. Acrescente-se a isso que os estudos de produção e comunicação científica de diversos campos científicos e profissionais são realizados no campo da Ciência da Informação, possibilitando a compreensão ligeira de um processo de integração disciplinar com esses campos. Além disso, pode-se perceber também a forte presença do discurso da integraçáo disciplinar no item "2 Formação Profissional e Mercado de Trabalho". Isso se deve, em grande parte, ao discurso de que o profissional da informação deve estar sempre atualizado e possuir múltiplas competências e habilidades, em virtude do mercado globalizado. Acrescente-se a isso que da mesma forma que existem diversas ciências atuando no campo informacional, há profissionais que são caracterizados nessa perspectiva, apenas para citar alguns, tem-se Administradores, Arquivistas, Bibliotecários, Contadores, Documentalistas e Cientistas da Computação, entre outros.

Por outro lado, percebe-se também que, exceção feita aos itens destacados anteriormente e ao item "4 Estudos de Usuários, Demanda e Uso de Informação”, uma distribuição equilibrada do discurso da integração disciplinar nas áreas. Este se destaca curiosamente com o menor índice, embora seja reconhecidamente uma área de estudo bastante complexa. Não se pode esquecer que um dos fundamentos da epistemologia interdisciplinar, de acordo com Pombo (2003), corresponde ao alcance do abismo da complexidade, ou seja, ao alcance de zonas do objeto de estudo que o olhar disciplinar especializado náo poderia ver.

\section{Considerações finais}

Com base nas discussões empreendidas no campo teórico-metodológico e nas análises empíricas realizadas em parte significativa da produção da Ciência da Informação, no Brasil, duas questóes parecem sobressair: a presença do discurso de integração disciplinar e sua dispersão na literatura e, mais precisamente, nos discursos individuais dos pesquisadores.

No que concerne à presença do discurso de integração disciplinar, pode-se dizer que se constitui na ratificação de um discurso fortemente veiculado na produçáo científica da área, uma vez que existe, no Brasil, uma aproximação consensual por parte dos autores a respeito da natureza interdisciplinar da Ciência da Informaçáo. 
Por outro lado, conforme se destacou anteriormente, faz-se necessário observar a complexidade dessas construçóes integradoras e as implicaçóes delas decorrentes, sobretudo, no desenvolvimento de linguagens comuns e na adequação de conceitos, teorias e metodologias advindos de outros campos e/ou áreas de estudo. A Ciência da Informação precisa, em primeira instância, constituir seu campo teórico e epistemológico de forma minimamente consolidada para atuar ativamente no processo interdisciplinar.

A dispersão da produção científica sobre a integração disciplinar, aliada ao estado de transiência da autoria, se configura como elemento de maior preocupaçáo, uma vez que aponta para certa imaturidade nas discussóes, nas análises e nas estratégias desenvolvidas na prática científica dessa área da Ciência da Informação. A pesquisa empírica evidencia uma dificuldade na investida de estudos teórico-metodológicos sobre a interdisciplinaridade. Embora essa constatação já venha sendo apontada por alguns autores, faz-se necessário maior dedicação à compreensão da epistemologia interdisciplinar na Ciência da Informação, principalmente, porque ela vem sendo assumida como um dos fundamentos do seu campo científico. Nessa perspectiva, esta pesquisa continuará buscando aprofundamento na compreensão das formaçóes discursivas e do funcionamento do discurso da integração disciplinar, com o intuito de melhor compreensão de suas implicaçóes para o campo.

Pode-se concluir que há fortes indícios de que a dificuldade por que passa a Ciência da Informação nas construçôes disciplinares pode se encontrar vinculada às práticas interdisciplinares de primeiras aproximaçóes, possivelmente bastante presentes.

\section{Referências bibliográficas}

Bachelard, G. (1996). A formação do espirito cientifico: contribuição para uma psicanálise do conhecimento. Rio de Janeiro: Contraponto. 314p.

Bourdieu, P. (1983). O campo científico. In: ORTIZ, R. (org.). Pierre Bourdieu: Sociologia. São Paulo: Ática. Cap. 2, p. 122-155.

Buckland, Michael K. (1991). Information as thing. Journal of the American Society for Information Science (JASI), v. 45, n. 5, p. 351-360. Disponível em: <http://people.ischool.berkeley. edu/ -buckland/thing.html>. Acesso em: 16 jul. 2008.

Capurro, R. (2003). Epistemologia e Ciência da Informação. In: ENCONTRO NACIONAL DE PESQUISA EM CIÊNCIA DA INFORMAÇÃO, 5, 2003, Belo Horizonte. Anais... Belo Horizonte: UFMG. 1 CD-ROM.

DIAS, E. W. (2002). O específico da Ciência da Informação. In: Aquino, M. A. O campo da Ciência da Informação: gênese, conexôes e especificidades. João Pessoa: Editora Universitária/ UFPB. p. 87-99.

Domingues, I. (2005). Em busca do método. In: Domingues, Ivan (org.). Conhecimento e transdisciplinaridade II: aspectos metodológicos. Belo Horizonte: Editora da UFMG. Cap. 1, p. $17-40$.

Gonzáles de Gomez, M. N. (2000). Metodologia de pesquisa no campo da Ciência da Informação. DataGramaZero - Revista de Ciência da Informação, v. 1, n. 6, out. Disponível em: < http:// dgz.org.br/dez00/Art_03.htm>. Acesso em 06 abr. 2007.

Kuhn, T. (2007). A estrutura das revoluçōes científicas. São Paulo: Perspectiva. 260p. 
Le Coadic, Y. (1996). A Ciência da Informação. Brasília, DF: Brinquet de Lemos/Livros. $119 \mathrm{p}$.

Morin, E. (2003). Da necessidade de um pensamento complexo. In: Silva, J. M. (Org.). Para navegar no século XXI. 3. ed. Porto Alegre: Meridional. p. 19-42.

Morin, E. (200-?). Sobre la interdisciplinaridad. Disponível em: http://www.pensamientocomplejo. com.ar. Acesso em: 25 jul. 2009.

Oddone, N., \& Gomes, M. Y. F. S. F. (2004). Os temas de pesquisa em Ciência da Informação e suas implicaçōes politico-epistemológicas. In: Cinfor - Encontro Nacional De Ciência Da Informação, 5, 2004, Salvador. Proceedings... Salvador. Disponível em: <http://www.cinform. ufba.br/v_anais/artigos/nancioddone.html>. Acesso em: 20 maio 2009.

Pombo, O. (2003). Epistemologia interdisciplinar. In: Seminário Internacional Interdisciplinaridade, Humanismo, Universidade. Porto, 2003. Anais... Porto. p. 1-29. Disponível em: <http://www. humanismolatino.online.pt/v1/pdf/C002_11.pdf>. Acesso em: 16 set. 2008.

Pombo, O. (1994). Interdisciplinaridade: conceito, problemas e perspectivas. In: POMBO, Olga; Levy, T., \& Guimarães, H. A interdisciplinaridade: reflexão e experiência. 2. ed. Lisboa, Portugal: Texto, 1994. Cap. 1, p. 8-14. Disponível em: < http://www.educ.fc.ul. pt/docentes/opombo/mathesis/interdisciplinaridade.pdf $>$. Acesso em: 15 set. 2008.

Saracevic, T. (1996). Ciência da Informação: origens, evolução e relações. Perspectiva em Ciência da Informação. Belo Horizonte, v. 1, n. 1, p. 41-62, jan./jun.

Silva, Amando Malheiro da. (2008). Notas sobre a Ciência da Informação I. Bad nort blog, 14 maio. Disponível em: < http://nortebad.wordpress.com/2008/05/14/notas-soltas-sobreciencia-da-informacao-1/>. Acesso em: 26 fev. 2009.

Agradecemos à FAPEAL (Fundação de Amparo à Pesquisa do Estado de Alagoas), pelo financiamento desta pesquisa, que representa um importante suporte para a sua realização. 